\title{
O PAPEL DO SUJEITO EM UMA ENCICLOPÉDIA ONLINE
}

\author{
Gláucia da Silva Henge
}

RESUMO: This text seeks to review the notion of subject from the perspective of discourse analysis to investigate the established designation for those who edit the online encyclopedia Wikipedia. For this, other important notions are rescued, such as: image, discoursive place, meaning and memory. Going through the formulations components of the encyclopedia, we can see the slides of meaning and the game of powers between the speeches, been emerging in the subjectivity of speech through an idealization. The Wikipedian would be, then, the correspondent at the plan of designation of an imaginary construction of the figure of an internet user as the one who applies all web resources and who is free to express himself, exchange with other internet users and who is an encyclopedist inside the virtual universe.

PALAVRAS-CHAVE: sujeito, discurso, wikipedista, enciclopédia, imagem.

Vivemos tempos em que com poucos cliques em frente ao computador, um universo de textos se revela aos nossos olhos. Com mais alguns cliques, realizamos buscas e percorremos inúmeras páginas, caindo, mais cedo ou mais tarde, num website de buscas. Onde encontrar algo? O que significa tal coisa? E o website nos encaminha para uma "enciclopédia online". Essa narrativa, simples e óbvia, ocorre milhares de vezes todos os dias, quando um estudante recebe um tema para pesquisa, quando um internauta quer obter alguma informação, quando alguém quer uma definição rápida que "sane" sua dúvida ou curiosidade. Tempos de internet. Tempos de rapidez.

Nesse movimento de busca/encontro de "conteúdos, o conhecimento emerge como algo que se busca e que se "pega". Uma enciclopédia online onde todos podem escrever e pesquisar torna-se um sucesso de acessamentos, pois disponibiliza "tudo". Como encarar tudo isto do ponto de vista discursivo? Como esses efeitos de sentido se cristalizam como evidências? Ao tomarmos uma enciclopédia online, então, como objeto de estudo, percebemos que redes discursivas se estabelecem, se enredam e se sobrepõe na configuração dos sentidos e dos sujeitos envolvidos nessa trama.Assim, buscamos neste artigo abordar a discursivização do sujeito na Wikipédia ${ }^{1}$, no que diz respeito aos usuários/internautas que a escrevem e a lêem, sob a imagem do que denominou-se o "Wikipedista". A Wikipédia teve sua origem no início dos anos 2000, nos EUA, e foi criada com o objetivo de ser uma enciclopédia constantemente ampliada e reescrita pelos seus próprios leitores/usuários. Sucesso de acessamentos, alvo de polêmicas, preferência dileta de estudantes... eis nosso objeto de investigação.

Mestre pelo Programa de Pós Graduação em Letras/UFRGS, Especialidade Teorias do Texto e do Discurso. http://pt. wikipedia.org 
Na Wikipédia há uma "nomeação/determinação" daqueles que a escrevem. Essa designação estabelece uma espécie de marca/identificação de quem a elabora, formando uma comunidade de usuários aptos e supostamente interessados em fazê-la prosperar. $\mathrm{O}$ surgimento dessa designação carece de uma análise discursiva que problematize e coloque em evidência o caráter dessa relação entre sujeitos, marcados pelo/no discurso acerca da mobilização dos saberes no espaço discursivo de uma enciclopédia online.

Em um primeiro momento, então, percorrermos a noção de sujeito e verificarmos como as relações entre os sujeitos se dão nesse espaço de discursivização do conhecimento. Em seguida, discutiremos essa imagem do "wikipedista", como um lugar discursivo construído entre os discursos que constituem a própria enciclopédia online, tão acessada e alvo de tantas discussões para, finalmente, percorremos os movimentos de sentido durante as práticas de discursivização da enciclopédia.

\section{O SUJEITO NA PERSPECTIVA DISCURSIVA}

Parece-nos significativo iniciar este estudo resgatando o percurso da noção de sujeito a partir do quadro epistemológico da $\mathrm{AD}$, pois, ao definir este quadro, Pêcheux \& Fuchs (1997, p.163) convocam três regiões do conhecimento: o materialismo histórico, a lingüística e a teoria do discurso e esclarecem que "estas três regiões são, de certo modo, atravessadas e articuladas por uma teoria da subjetividade (de natureza psicanalítica)" (Id.ib. 1997, p.164).

Nesta primeira menção efetiva à psicanálise, ao explicitar uma noção de sujeito de natureza psicanalítica, Pêcheux e Fuchs estão trazendo ao campo da AD os estudos de Jacques Lacan, quando este pensa o inconsciente (Freud) em sua relação com a linguagem (Saussure). Pêcheux conhecia as proposições de Lacan acerca do sujeito e, enquanto aluno de Althusser, dispôs-se aproximar o trabalho com o inconsciente do primeiro com o trabalho da ideologia do segundo. Pêcheux buscava "abrir uma fissura teórica e científica no campo das ciências sociais" (HENRY, 1997, p.14) e para tanto, apoiou-se sobre "o que lhe parecia já ter estimulado uma reviravolta na problemática dominante das ciências sociais: o materialismo histórico tal como Althusser o havia renovado (...), a psicanálise tal como a formulou Lacan, bem como certos aspectos do (...) estruturalismo" (Ib.id., 1997, p.14). É dessa congruência de formulações que emerge o sujeito da $\mathrm{AD}$, constituído como tal na imbricação da ideologia, da linguagem e do inconsciente.

$\mathrm{Na}$ Wikipédia o que está em jogo é o conhecimento humano e como ele pode ser "registrado", "armazenado", "editado" por qualquer internauta; este trabalho de discursivização dos saberes pelos sujeitos convoca uma abordagem profundamente reflexiva acerca dos embates ideológicos e das falhas dos sujeitos sob/sobre/em a língua que "materializa" essa enciclopédia. Portanto, a noção de sujeito na perspectiva discursiva mostra-se altamente pertinente para que percebamos que sujeitos são os "wikipedistas", isto é, como eles se constroem como tais e se marcam pela linguagem ao longo das páginas da enciclopédia.

Imagem, linguagem e impossibilidade são, sob a ótica lacaniana, os fundamentos da constituição do sujeito. Um sujeito psicanalítico, dotado de inconsciente, desejante e definido pela sua relação com o Outro.

Já sob a ótica althusseriana, ideologia, materialidade e interpelação são os fundamentos da constituição do sujeito. Um sujeito ideológico, invocado por representações das suas condições de existências e definido pela sua relação com o Sujeito da ideologia. 
Esses sujeitos não são "indivíduos, pessoas, organismos", mas, valendo-se da expressão de Althusser, são sujeitos concretos, cujo processo de constituição se dá de certo modo regular e universal.

Como pensar, então, esses processos (psíquico e ideológico) conjuntamente? É o que Pêcheux e seu grupo fazem, quando aproximam a linguagem da ideologia, propondo a noção do discurso, sendo que é a noção de sujeito em sua relação com a linguagem e com a ideologia que permite essa aproximação. A Análise do Discurso vai então apropriar-se da noção de sujeito e reformulá-la.

As noções de Althusser e Lacan são explicitamente retomadas e articuladas por Pêcheux, como se pode ver na passagem em que ele cita a tese de Althusser na qual o indivíduo é interpelado em sujeito para livremente submeter-se às ordens do Sujeito e diz:

\begin{abstract}
Se acrescentarmos, de um lado, que esse sujeito, com um $\mathrm{S}$ maiúsculo - sujeito absoluto e universal -, é precisamente o que J.Lacan designa como o Outro (Autre, com A maiúsculo), e, de, outro lado, que, sempre de acordo com a formulação de Lacan "o inconsciente é o discurso do Outro", podemos discernir de que modo o recalque inconsciente e o assujeitamento ideológico estão materialmente ligados, sem estar confundidos, no interior do que se poderia designar como o processo do Significante na interpelação e na identificação, processo pelo qual se realiza o que chamamos as condições ideológicas da reprodução/transformação das relações de produção. (PÊCHEUX, 1988, p.133-4)
\end{abstract}

Assim, Pêcheux mobiliza a noção de sujeito, presente nos dois autores, e aponta para um modo novo e diferenciado de percebê-la, pois fica, então, a necessidade de debruçar-se sobre o processo da linguagem (Significante) na interpelação ideológica e na identificação do sujeito como tal. Essa teoria não-subjetiva da subjetividade é que vai "fundar, em seu princípio, a teoria (materialista) dos processos discursivos" (PÊCHEUX, op.cit., p.134). Inconsciente e ideologia, são, portanto, elementos da subjetividade, cada um a seu modo, distintamente mobilizados, mas que, juntos vão permitir pensar o sujeito, enquanto um significante numa cadeia de significantes, conforme Lacan, afetado pela linguagem na sua constituição e invocado pela ideologia enquanto representação de relações imaginárias das condições reais de existência. Pêcheux sintetiza o caráter comum às "estruturas-funcionamentos", chamadas Inconsciente e Ideologia, o "dissimular sua própria existência no interior mesmo do seu funcionamento, produzindo um tecido de evidências subjetivas" (PÊCHEUX, op.cit., p.153).

Essa noção de sujeito faz desvanecer a certeza de um sujeito como centro, origem, pois "um deslocamento conceitual se produziu ao se teorizar o sujeito em sua sujeição à esfera do econômico e à série de significantes que o constitui, o aliena e o divide." (MARIANI, 2009), isto é, um sujeito autofundante, ciente de si e senhor de suas vontades e palavras é redimensionado e problematizado a partir desse deslocamento que traz à tona o papel da sociedade, do mercado e da linguagem na constituição do sujeito.

Na figura da interpelação, se junta à constituição do sujeito a constituição do sentido, uma vez que é nela que "se pode captar que se fala do sujeito, que se fala ao sujeito, antes de que o sujeito possa dizer "Eu falo"” (PÊCHEUX, 1988, p.154) além de ser nela que "o sujeito é chamado à existência" (id.ib., 1988, p.154), como na SD abaixo onde o "eu" (nós) em relação com o "você" marca a evidência do sujeito em sua relação com o outro e com o Outro. 
SD1 - Uma das coisas mais importantes que deve saber é que, para mantermos o nosso objetivo, nós necessitamos seguir algumas normas que lhe pedimos humildemente para respeitar.

Ou seja, a ideologia (na interpelação) e o inconsciente (na identificação) determinam o processo do significante (ser sujeito) e também determinam o sentido, pois é pelo viés do sentido que se percebe esse jogo de forças entre os discursos do Outro e as lutas ideológicas em que emergem os sujeitos. Na Wikipédia, buscamos identificar essa constituição do sentido, tomado como evidente devido ao trabalho da ideologia e do inconsciente. Os sujeitos analisados emergem dessa congruência entre os discursos outros no intervalo entre os significantes do inconsciente e também da invocação da ideologia que representa as relações com as condições reais de existência. Há a evidência de ser sujeito e de dizer o que se diz. Por isto que "se é sujeito pela submissão à língua, na história. Não se pode dizer senão afetado pelo simbólico, pelo sistema significante. Portanto não há sujeito nem sentido sem o assujeitamento à língua" (ORLANDI, 2009, p.109)

Essa evidência de ser sujeito é designada como a evidência elementar. Ela é possibilitada pelo pré-construído, isto é, "uma discrepância pela qual um elemento irrompe no enunciado como se tivesse sido pensado antes, em outro lugar, independentemente" (PÊCHEUX, 1988, p.156), é esse efeito de já pensado, o préconstruído, que funciona como "a modalidade discursiva da discrepância pela qual o indivíduo é interpelado em sujeito... ao mesmo tempo em que é sempre-já-sujeito" (PÊCHEUX, op.cit., p.156). A essa discrepância está associada a noção de funcionamento da contradição, sendo que esta é constitutiva na evidência do sujeito e do sentido. Os sujeitos da Wikipédia estão sob esse funcionamento, assim como a presença do pré-construído permeia e sustenta os dizeres, pois lhes dão a força da evidência do sentido que é dito por um sujeito "que diz", consciente de suas palavras e pensamentos. Nesse efeito do sujeito como causa de si mesmo, Pêcheux preocupa-se em salientar que a noção de Lacan em que o significante é aquilo que representa o sujeito para um outro significante, não leva a uma supervalorização das palavras, mas sim, reforça a importância de investigar "de que modo todos os indivíduos recebem como evidente o sentido do que ouvem e dizem, lêem ou escrevem (do que eles querem e do que se quer lhes dizer, enquanto "sujeitos-falantes"” (PÊCHEUX, op.cit., p.157).

A ideologia invoca (ou recruta) o indivíduo em sujeito. A linguagem o constitui como sujeito através do discurso do Outro e do desejo do outro. Numa evidência elementar, se é sempre-já-sujeito: falado, esperado, desejado. Assim, cada sujeito responde a essa invocação, pois é objeto de desejo do Outro e está em relação material de existência com esse Outro, pela linguagem, mas sempre como um efeito de evidência.

Para a psicanálise, pelo registro Imaginário, o sujeito se identifica como eu está fundido imaginariamente numa completude (de desejo e de a alíngua), mas com a presença de um terceiro elemento, a função paterna, há o fim dessa completude imaginária e o bebê inscreve-se noutro registro, o Simbólico, o mundo da linguagem, mas que sempre será acompanhado, enquanto sujeito, da falta, do impossível de ser simbolizado, que é o Real.

A AD vai apropriar-se desses registros aproximando-os da teoria das formações sociais. Assim, para a AD, "o discursivo é a ligação entre a ordem do imaginário - do ideológico, e a ordem simbólica - a ordem das palavras" (MORALES, 2008, p.43) sendo que o que determina essa ligação é exatamente a "relação da linguagem com a 
história, em seus mecanismos imaginários". O imaginário e o simbólico sustentam o real, o que resiste à simbolização. Desta forma, a AD relaciona o real ao inconsciente e à história, propondo um real da língua relacionado com a ordem da língua "ordem significante marcada pela falha" (MORALES, op.cit., p.44) e um real da história relacionado com a ordem da história "lugar do equívoco, que impede o sucesso total das identificações e obriga o sujeito a tomar uma posição, a interpretar" (MORALES, op.cit., p.44). Leandro Ferreira vai acrescentar a esse registro em AD, o real do sujeito. Assim, nessas acepções de real "estão presentes o traço da incompletude e da não sistematicidade (...) levando em conta 'as faltas' e as 'as falhas' da estrutura; e ao trabalho da ideologia, com seu ritual de assujeitamento, também não isento de falhas". (LEANDRO FERREIRA, 2007, p.107).

O sujeito, portanto, é constituído na relação da linguagem com ideologia, ou ainda, na relação língua/história; ele, quando invocado pela ideologia a ser sujeito do seu dizer, se submete às determinações da história e da língua, assujeitando-se. Ainda que as representações se simbolizem, sempre há uma incompletude, uma falta essencial, e é essa falta constitutiva que permite o deslizamento, a não-identificação plena entre significantes (sujeito/sentido), e assim, a língua falha revelando pelo equívoco a contradição na história (como nos mostra Pêcheux, 2006). A realidade material, ou melhor, as condições reais de existência, em suas contradições, que interferem e determinam a língua, correspondem à linguagem na dimensão psíquica do sujeito de uma formação social. É o que esclarece Leandro Ferreira ao pensar a morada do sujeito como a morada da linguagem: "o lugar do assujeitamento, representado pela ideologia, e o lugar do desejo, representado pelo inconsciente, se encontram e se constituem na linguagem” (LEANDRO FERREIRA, 2007, p.105).

Como é a linguagem que constitui e compõe a Wikipédia sustentando-a como tal, e é a linguagem esta correspondente na dimensão psíquica do sujeito das suas condições reais de existência pelo trabalho da ideologia, podemos concluir que os sujeitos envolvidos com a configuração de uma enciclopédia virtual, então, são da ordem dessa relação da linguagem com a ideologia.

A noção de sujeito, apropriada pela Análise do Discurso, ainda implica na dupla afetação (pessoal e social) do sujeito, como fala Indursky: "o sujeito é interpelado ideologicamente, mas não sabe disso e suas práticas discursivas se instauram sob a ilusão de que ele é a origem de seu dizer e domina perfeitamente o que tem a dizer" (INDURSKY, 2008, p.11). São os dois esquecimentos de que falam Pêcheux \& Fuchs (PÊCHEUX \& FUCHS, 1997, 176-7): o esquecimento número 1, inconsciente, da ordem da constituição, o qual sua zona "é inacessível ao sujeito (...) aparece como constitutivo da subjetividade na língua", isto é, o sujeito esquece que é interpelado pela ideologia ao dizer; e o esquecimento número 2, pré-consciente ou consciente, da ordem da formulação, num "efeito de ocultação parcial e de identificar aí a fonte da impressão de realidade do pensamento para o sujeito ("eu sei o que eu digo", "eu sei do que falo")". Enquanto o primeiro esquecimento é inacessível ao sujeito, o segundo lhe permite retornar aos seus dizeres, antecipar outros... e assim, ele tem a ilusão de subjetividade e as formas de realizar, na linguagem, essa subjetivação. Essa subjetivação se dá nos artigos da enciclopédia online, por força e obra das práticas discursivas dos "wikipedistas", como uma imagem que percorre e subsiste a todo e qualquer dizer que emerge na enciclopédia.

\section{A IMAGEM DO WIKIPEDISTA}


A enciclopédia virtual é um universo de possibilidades de novos modos de relação entre os sujeitos e entre eles e o conhecimento nos campos: acadêmico, escolar, interpessoal, político, econômico, tecnológico etc. Esse jogo de forças, no plano discursivo, se faz presente de diferentes modos, entre eles na menção a aquele que se coloca na posição de autor/editor da Wikipédia. A este, dirigem-se enunciados tais como o da SD abaixo.

SD2 - Wikipedistas possuem suas próprias páginas de usuário, mas que devem apresentar somente informações relevantes para trabalhar numa enciclopédia.

Quando Pêcheux define a noção de discurso como "efeito de sentidos entre os pontos A e B" (PÊCHEUX, 1997a, p.82) ele toma A e B (destinador e destinatário) do esquema jackobsoniano e os pensa como elementos, e não organismos físicos presentes. Para ele, esses elementos designam, então, lugares determinados na estrutura de uma formação social. Esses elementos (sujeitos), portanto, ocupam na formação social determinados lugares e não outros, ou seja, os lugares sociais são o espaço das práticas sociais que, pela interpelação ideológica, vão constituir as práticas discursivas.

Esses lugares estão representados, porém transformados, nos processos discursivos: como imagens. Assim, "o que funciona nos processos discursivos é uma série de formações imaginárias que designam o lugar que A e B se atribuem cada um a si e ao outro, a imagem que eles fazem de seu próprio lugar e do lugar do outro" (PÊCHEUX, 1997a, p.82).

Essas imagens ao representarem de modo transformado, no plano do discurso, lugares estabelecidos em uma dada formação social, seguem regras nas quais há o estabelecimento de "relações entre as situações (objetivamente definíveis) e as posições (representações dessas situações)" (PÊCHEUX, 1997a, p.82). Portanto, na passagem do plano objetivo (concreto) para o plano discursivo (lingüístico-histórico) o que se tem é uma relação inextinguível das práticas sociais materiais e todo o jogo de forças das relações de produção (condições materiais de existência) com as práticas discursivas, nas quais essas forças vão atuar no plano lingüístico pela colagem do sentido no trabalho da ideologia. Não há, então, distinção entre "realidade" e "linguagem", ou melhor, a realidade define a linguagem e a linguagem define a realidade, sempre pela/na Ideologia.

Podemos visualizar o trabalho de formações imaginárias distintas, definindo, delimitando, direcionando (e porque não) moldando o funcionamento discursivo dos artigos que constituem o "corpo" da Wikipédia, isto é, as páginas do site.

De um lado, tem-se a imagem do enciclopedista: aquele que escreve enciclopédias. Logo, as formações imaginárias em torno desse lugar social/posição discursiva vão formular, no discurso, os sentidos de quem escreve, como escreve, o que escreve numa enciclopédia, e mais do que isso, o que é uma enciclopédia, para que serve, o que pode haver e o que não pode haver nela, etc.

Por outro lado, tem-se a imagem do internauta: aquele que navega pela rede mundial de computadores. Logo, as formações imaginárias vão formular, por sua vez no discurso, os sentidos de quem utiliza a internet, como a usa, para que fins a usa, e mais do que um senso utilitarista, quem se é quando se está on-line, o que e como se escreve e se lê quando se está no espaço da virtualidade, etc.

A partir dessas duas imagens bastante diferentes entre si, é que as formulações vão ser construídas no espaço do artigo, por sujeitos do discurso que, buscando atender 
a essas duas imagens simultaneamente, passam a uma idealização que culmina na figura de uma terceira imagem: a imagem do wikipedista. É o wikipedista, a correspondência, no plano da designação, de uma construção imaginária da figura do internauta como aquele que se vale de todos os recursos da web, que tem liberdade para expressar-se e trocar com outros internautas e que é um enciclopedista dentro do universo virtual.

Se a língua é determinada pela história e as condições de produção em uma formação social são determinantes do sentido, é preciso perceber como a realidade intervém nas modalidades discursivas do funcionamento subjetivo, pois, do contrário, não haveria relação entre discurso e sociedade. Como vimos, as formações discursivas correspondem no campo do discurso ao jogo de forças e poder estabelecido numa formação social através das relações de poder entre os sujeitos. Sujeitos porque a ideologia é "o processo de interpretação dos indivíduos em sujeitos" (PÊCHEUX, 1988, 217). Os sujeitos se relacionam pelas práticas sociais, mas devido ao papel da linguagem, não há como delimitar o que seriam "práticas puramente lingüísticodiscursivas", logo, cremos poder definir a realidade como conjunto de práticas sóciodiscursivas, já que não há sociedade sem linguagem, nem linguagem sem sociedade.

Como então, as práticas interferem na tomada de posição? Ou ainda, como as posições-sujeito dentro de uma formação discursiva correspondem no discurso às relações na história? Se na formação social há lugares sociais a partir dos quais são realizadas as práticas sócio-discursivas, na formação discursiva há lugares discursivos a partir dos quais são realizadas as tomadas de posição e a ocupação das posições-sujeito.

Isto se aproxima da distinção proposta por GRIGOLETTO $(2008$, p.58) quando a autora afirma que a formação social "compreende o espaço empírico que, por sua vez abriga as diferentes formações ideológicas, as quais interagem com as relações de poder (...) determinando o lugar social que o sujeito ocupa na sociedade", havendo, portanto, um espaço da prática social. Já a formação discursiva "compreende o espaço discursivo que, por sua vez, abriga o lugar discursivo que se relaciona tanto com a forma-sujeito quanto com as diferentes posições-sujeitos" (GRIGOLETTO, op.cit., p.58), sendo, portanto, espaço de prática discursiva. Longe de ser esta uma mera distinção entre realidade (social) e linguagem (discurso), Grigoletto está apontando para um intrincamento constitutivo e determinante na tomada de posição já que "o lugar social é feito da prática discursiva ao mesmo tempo em que o lugar discursivo é efeito/está determinado pela prática social" (GRIGOLETTO, op.cit., p.58).

Neste ponto parece-nos crucial retomar Pêcheux (AAD-69) quando ele diz que os lugares determinados na estrutura de uma formação social estão representados nos processos discursivos, e que esta representação se dá como transformação não-objetiva. E mais ainda, de que há regras de projeção em qualquer formação social que estabelecem as relações entre as situações e as posições e que o lugar é designado nos processos discursivos pelas formações imaginárias. Logo, podemos deferir que o lugar social corresponde no discurso à imagem ou lugar discursivo, sendo que esta correspondência não é biunívoca tampouco objetiva. Mas sim, que a imagem é um construto no campo do discurso das relações na formação social pelas práticas.

Então, o sujeito do discurso ao ocupar uma posição-sujeito se relaciona com a forma-sujeito via lugar discursivo, via imagem, ou seja, há lugares discursivos que operam "o trabalho na e sobre a forma-sujeito (os deslocamentos, as identificações, as contra-identificações)" (GRIGOLETTO, op.cit., p.65).

No caso da Wikipédia, temos isto muito claro: há duas imagens já conhecidas: a imagem do enciclopedista e a imagem do internauta. Fazendo um deslocamento e 
compreendendo-as como lugares discursivos, poderemos perceber como cada uma vai viabilizar a tomada de posição dos sujeitos dentro da formação discursiva. Além disso, um lugar discursivo não é "propriedade" da formação discursiva, mas sim, uma representação que a habita.

Como podemos verificar, o lugar discursivo do Wikipedista distingue-se do lugar discursivo do internauta por editar a "enciclopédia on-line", agregando e organizando o "conhecimento" que ela comporta; mas se distingue também do lugar discursivo do enciclopedista por não se tratar de uma enciclopédia em papel, com edições delimitadas e textos "prontos", nem ser um especialista. Mas fica a questão: quem é o sujeito que ocupa esse lugar discursivo nomeado "wikipedista"? Ou melhor, quem são esses sujeitos envolvidos? Como eles afetam e são afetados pela linguagem? Os sujeitos a analisar aqui estão direta e essencialmente ligados aos sentidos estabelecidos na enciclopédia virtual, pois é pela história na língua que resgatamos as relações histórico-ideológicas que determinam a formulação e a circulação dos saberes na Wikipédia.

\section{O SUJEITO NA/DA WIKIPÉDIA: O WIKIPEDISTA}

O funcionamento discursivo da Wikipédia repousa e se configura de modo crucial na questão dos sujeitos envolvidos em sua "construção" e pelo modo com que "constroem-na". Então, a partir dessa compreensão de como as relações entre linguagem, inconsciente e ideologia vão permear os dizeres de cada "falante", poderemos investigar: quem é o sujeito na/da Wikipédia? Para tanto, mergulhamos nas discursivizações que compõe a materialidade da enciclopédia on-line, e resgatamos as seqüências discursivas que permitem, pela análise discursiva, a problematização do sujeito em questão sob a égide da imagem de Wikipedista.

$\mathrm{O}$ wikipedista, também tomado como editor, usualmente apresenta-se como coletividade: nós, a comunidade de editores, sendo aquele que não apenas lê e navega pelas páginas através do links, mas que também "interfere" nos artigos, editando-os.

Entretanto, há padrões de "interferência" de diferentes graus, marcados por práticas de edição (tomadas como gestos, por constituírem interpretação) bastante distintas entre si. Há wikipedistas que buscam informações e eventualmente contribuem, há aqueles que contribuem regularmente e que passam a ter "privilégios" como o direito a voto ou à sinalização de problemas com o artigo (uso de tags), há aqueles que não somente editam, votam, mas que também podem gerenciar os artigos, excluindo-os ou bloqueado suas edições (são os administradores)... Enfim, na figura do wikipedista encerra-se um forte jogo hierárquico marcado pelo domínio e pelo poder de atuação na enciclopédia.

É também na figura do wikipedista, que tomamos como lugar discursivo, que podemos constatar a existência de um sujeito discursivamente idealizado: um sujeito da Wikipédia: o sujeito wikipedista, aquele que edita e que se identifica, participando ativamente da escrita dos artigos (contribuições válidas).

Esta distinção fica muito clara também na página de "boas vindas" através da interlocução que se trava entre o sujeito (wikipedista) e o leitor/usuário sob o tópico comunidade Wikipédia:

SD3 - Enquanto lê este texto, pessoas comuns como você e nós constroem laboriosamente este projeto. Inclusivamente neste momento pode estar alguém a alterar esta mesma página. Não precisa estar registado (sic) para contribuir, mas 
é claro que temos todos o maior prazer em conhecer quem colabora connosco (sic).

Aqui, chamamos a atenção para o uso dos pronomes empregados. Há uma diferenciação muito acentuada entre você (usuário comum, leitor comum, ou seja, um sujeito na Wikipédia) e nós (aqueles que realmente fazem a Wikipédia), na qual percebemos que o uso da segunda pessoa do singular reforça o isolamento, a solitude de quem simplesmente navega pela web, enquanto que o uso da primeira pessoa do plural marca a socialização, a existência de uma comunidade de convívio e mútuo e unidade, comunidade esta que aguarda e recebe afetuosamente aqueles que desejarem integrá-la, mas que exclui "você" de "alguém". Essa integração do indivíduo isolado numa comunidade que o recebe se dá, na materialidade discursiva, pela conjunção como na definição que une e iguala ambos: pessoas comuns como você e nós constroem.

Entre os wikipedistas há normas a serem seguidas e que, para aqueles que desejam ingressar nesta comunidade mediante a inclusão como editor, devem ser respeitadas... Os sentidos emanam de um discurso autoritário, no qual se evidenciam as regras e "educadamente" se as impõe. Essas regras estão sob o título de "normas de conduta". Essas normas vão construir, discursivamente, a imagem do wikipedista, imagem esta construída sobre um efeito de apagamento da existência de práticas de edição distintas e de modos diferentes pelos quais os sujeitos se relacionam com a enciclopédia.

Podemos afirmar, então, que o sujeito da Wikipédia corresponde ao lugar discursivo do Wikipedista. Ou seja, há um sujeito (afetado pela história e interpelado pela ideologia) que, pela linguagem, se inscreve em redes de sentidos que compõe a enciclopédia online enquanto materialidade. Essa materialidade é regulada por conjuntos de práticas discursivas que condizem e são reguladas por um lugar discursivo de sujeito, o wikipedista. Essas práticas se relacionam com os aspectos do dizer desse sujeito (imparcialidade, neutralidade, objetividade), bem como com a condição desse dizer (liberdade, responsabilidade) e com os saberes mobilizados nesse dizer (o conhecimento).

Porém, sabemos que a escrita da enciclopédia é realizada por sujeitos que se propõem a "encaixar" neste lugar discursivo, e no papel de editores, produzem efeitos de sentido na elaboração de artigos sobre o "conhecimento humano". Quais seriam esses efeitos? Como se daria esse "encaixe" ao papel de editor?

$\mathrm{Na}$ enciclopédia, existem as páginas de discussão entre os wikipeditas, tratandose de um espaço destinado em cada verbete para que se discuta o "conteúdo" do artigo e que está separada (formando uma outra página distinta) da página do artigo em si. Essa separação virtu-espacial nos leva a perceber um primeiro movimento: de afastamento e segregação entre o autor e o artigo, ou melhor, entre o wikipedista e o "conhecimento enciclopédico"... Há a separação espacial e nodal entre o "conteúdo" e o "autor", assim, a página do artigo passa a ter um efeito de "imparcial" como se não possuísse vínculo algum com os editores, num esforço discursivo de apagar a evidência do sujeito no dizer. Além disso, a página de discussão passa a ser o único espaço no qual os membros da comunidade vão, de fato, interagir entre si, no que então seria a escrita colaborativa que configura toda a enciclopédia.

Mergulhando nas formulações presentes na Wikipédia, neste espaço para "discutir", fazemos isto selecionando seqüências nas quais há uma abordagem/definição dos próprios sujeitos envolvidos sobre a sua escrita na enciclopédia, exatamente porque esses trechos contêm vestígios de algo que constitui cada prática, mas que pode ainda 
não ser tão evidente aos sujeitos, gerando, portanto, a discussão. Ao tematizar o conteúdo de cada artigo, num esforço de fechamento dos sentidos, há o trabalho do sujeito sobre os sentidos e sobre o que seria o conhecimento.

Entre as centenas de discussões analisadas, tivemos a oportunidade de constatar que há uma série de recorrências entre elas, motivando a maior parte das intervenções nas páginas a que correspondem. Ou seja, há certas motivações que são determinantes para que o wikipedista tome a palavra e registre sua opinião/questionamento/dúvida. Destas, selecionamos a questão da imparcialidade e a questão da fonte da informação. Ambas as questões estão dispostas no site da enciclopédia como pertencentes às políticas oficiais da Wikipédia lusófona, sendo que a primeira diz respeito a um dos cinco pilares (ou princípios fundadores da enciclopédia) que explicita "a Wikipédia rege-se pela imparcialidade; o que implica que nenhum artigo deve defender um determinado ponto de vista" ${ }^{2}$; já a segunda diz respeito a uma diretriz de conteúdo da enciclopédia, a verificabilidade, onde "material verificável, neste contexto, significa que qualquer leitor deverá poder aferir que tal material foi já publicado por uma fonte fiável" 3 . Essas duas questões, relacionadas às "políticas oficiais da Wikipédia", são extremamente relevantes por constituírem mecanismos reguladores dos dizeres dos sujeitos. A partir desses dois "parâmetros" idealizados, os sujeitos vão se relacionar com os saberes regulados pela forma-sujeito da formação discursiva em que se inscrevem, regulando (ou tentando regular) seus dizeres, num esforço de adequação dos sentidos para que cheguem à evidência da imparcialidade e da verificabilidade.

Vejamos como isto se dá nas práticas dos sujeitos na Wikipédia através deste breve recorte que traz dois saberes ligados ao Wikipedista e que configuram uma exigência na discursivização do sujeito na enciclopédia on-line. Trata-se da noção de "imparcialidade" e da "fonte de informação".

\section{A imparcialidade}

O sentido uno, transparente, evidente emerge da estabilização de discursos num universo de domínio de uma determinada formação discursiva, assim, sob o efeito de evidência, uma rede de formulações se tece, trazidas pela memória da estratificação desnivelada que compõe o interdiscurso. Pela repetição, certos funcionamentos emergem como recursividade e trazem ao intradiscurso a série de referências que lhe garante determinado efeito. É assim que a ilusão de imparcialidade se concretiza no discurso, dando-lhe a aparência de neutralidade, numa tentativa de eximir o dizer de ser tendencioso ou partidarizado. Esse efeito, que mascara no fio do discurso as suas filiações de sentido com as formações discursivas e ideológicas, recrudesce a ilusão de assepsia na formulação. Mais do que uma característica historicamente atribuída ao objeto discursivo "enciclopédia", a suposta imparcialidade atende a uma exigência imaginária sobre a enciclopédia, por colocar "em círculo" e por "fazer circular" o conhecimento, ela é requisitada a ser indiferente, com algo frio e apático, completamente externo ao dizer, simplesmente armazenando-o.

Nesse sentido, na página de discussão do artigo sobre a cidade do Rio de Janeiro é travada uma grande disputa entre os editores a partir do fato de um dos editores anotar a expressão "parcial" no texto escrito que compunha o artigo. Essa notação se faz através de um recurso disponível aos editores de colocar tags, uma espécie de caixa de

2 http://pt.wikipedia.org/wiki/Wikipedia:Cinco_pilares

3 http://pt.wikipedia.org/wiki/Wikipedia:Verificabilidade 
texto que remete à imagem de uma etiqueta, isto é, trata-se de um recurso que permite classificar o artigo em um determinado aspecto. Bastante comum na Wikipédia, as tags funcionam como marcadores no início de cada artigo (logo abaixo do título) do que deve ser aprimorado, revisto, modificado em cada artigo, seguindo um padrão (textualizado) e fazem parte das instruções aos Wikipedistas como meio para o aprimoramento dos artigo, funcionando como um selo de observação/elogio/advertência/reprovação. As tags podem indicar, entre outras coisas, a necessidade de revisão do artigo, de acréscimo de fontes, de referência de pertencimento a um projeto maior, a classificação como artigo exemplar... e também, de que o leitor deve estar atento à parcialidade do texto, isto é, uma tag pode advertir que o artigo está violando a regra de imparcialidade da Wikipédia.

Assim, temos aqui, uma situação em que um wikipedista atribuiu a tag de imparcialidade ao artigo sobre a cidade do Rio de Janeiro. Tal classificação, portanto, implicaria o trabalho dos wikipedistas de tornar o artigo como um todo imparcial, novamente. A cobrança pela ilusão de imparcialidade é reforçado nas normas de conduta, onde a imparcialidade é priorizada e significada como ausência de pregação, isto é, sob um efeito de neutralidade no qual o sujeito se "dessubjetiva" e afasta o seu dizer do efeito primeiro de pertencimento. Observemos, então, um excerto da discussão entre os editores:

SD4 - Dicordo de você Hector, pricipalmente quando diz: "se a maioria discorda não posso fazer nada". Pode sim, retirar o tag parcialidade é o mínimo que você pode fazer para ser IMPARCIAL e justo. Se você quer que a seção sobre violência seja ampliada, então a amplie. Seria o mesmo que eu entrar na página de Recife e de São Paulo e indicá-la como PARCIAL, porque "no meu ponto de vista" o tópico de violência das duas deve ser ampliado. Porque EU ACHO que deve haver um tópico específico sobre o Jardim Angela ou Diadema, ou porque EU ACHO isso ou aquilo independente da opinião DA MAIORIA. Editar uma página incluindo uma tag sobre PARCIALIDADE por que "no meu ponto de vista" deveria ser feito isso ou aquilo, isso sim é exemplo claro de PARCIALIDADE.--FlaviaC (discussão) 14h53min de 15 de Março de 2008 (UTC)

Analisemos a oposição parcial x imparcial, sistematizando as formulações da SD.

\begin{tabular}{|l|l|}
\hline \multicolumn{1}{|c|}{ Parcial } & \multicolumn{1}{|c|}{ Imparcial } \\
\hline $\begin{array}{l}\text { Ponto de vista (eu) } \\
\text { (minha) opinião, eu acho }\end{array}$ & Ponto de vista da maioria \\
(injusto) & Opinião da maioria \\
\hline
\end{tabular}

Deste quadro, podemos perceber que há um discurso sobre a imparcialidade, que o toma como efeito de concordância entre a maioria. Esse efeito é alcançado pela ligação que o discursivo estabelece entre o ideológico e as palavras. Assim, para o sujeito duplamente afetado, o esquecimento de que não é origem do dizer, tampouco de que o que diz é da ordem do não-dito, permite que um sentido para "imparcial" se equivalha, parafrasticamente, a "maioria". Mais do que isto, a evidência desse sentido regula as práticas desse sujeito que, ao tentar ocupar o lugar discursivo de Wikipedista, "preenche" seu dizer acerca da advertência do artigo, interpretando-a como uma opinião pessoal. 
Todo esse funcionamento discursivo diz respeito a um trabalho da memória sobre a significação pelos sujeitos, em fazê-la a partir do lugar discursivo do wikipedista. Para tanto, os sentidos naturalizados como os de pertencimento a uma comunidade, de escrita pelos seus leitores e de responsabilidade sobre essa escrita se submetem a um sentido tomado como hegemônico: a imparcialidade deve ser seguida por todos em todas as circunstâncias.

Nesse deslizamento de sentido que verificamos de imparcial para opinião da maioria, podemos verificar a falha a que todo sujeito se submete pela linguagem, a incompletude do dizer e possibilidade de todo sentido tornar-se outro. Além disso, nessa formulação identificamos a tomada de posição do sujeito em identificação com FD do Enciclopedismo, cuja forma-sujeito preconiza e regula os saberes a partir do registro do conhecimento, mas sem que marcas do sujeito que o registra sejam evidentes. Assim, a solução está na distinção e apagamento do "eu" que seria sempre imparcial, logo indesejado, excluído por esta FD, para uma dominância da maioria, que seria sempre neutra, justa, sendo que o sentido de justiça é aqui associado ao de imparcialidade remetendo ao equilíbrio, ao bom senso, a não-tendenciosidade que cabe à enciclopédia. A questão da parcialidade, sem dúvida alguma, constitui um dos maiores conflitos entre os sujeitos na tentativa de ocupação do lugar discursivo de Wikipedista.

\section{A fonte verificável}

Todo dizer, que emerge na formulação, remonta ao enunciado que constitui o interdiscurso, assim, a cada dito, uma atualização dos enunciados possíveis se materializa no fio do discurso, configurando o sentido. Esse movimento dos dizeres desloca os elementos de saber por entre as regionalizações da ideologia, o que lhes garante certos efeitos de sentidos. Esse movimento ininterrupto dos sentidos, entretanto, tem como contraponto no sujeito a necessidade do efeito de originalidade do dizer, de pertencimento a este ou aquele sujeito. O efeito de evidência da origem, desta forma, repercute e culmina na ilusão de fonte. Isto é, para todo e qualquer dizer, a fonte seria a causa primeira, o espaço/tempo da criação, a sua nascente. A enciclopédia encerra mais uma vez, mediante sua busca de totalidade do saber, a exigência de o conhecimento por ela "registrado" seja verificável, ou seja, possa ser referenciado, retomado, acessado em diferentes momentos e espaços. Assim, unem-se duas arbitrariedades: a da localização do dizer, logo, a da sua origem. Essa relação diz respeito ao dizer como inédito em um certo "local" e depois,como mera repetição em outros locais. Na Wikipédia, a necessidade da verificabilidade do dizer em sua origem se concretiza como a regra de utilizar e citar fontes confiáveis das quais os artigos são "abastecidos" como dizer. Um artigo quando corresponde a esse efeito de legitmidade assegurada pela presença de menção a fonte passa a ter o status de "artigo em destaque", também mediante o uso de tags. Assim, a legititimidade de um artigo ou de uma fonte nada mais é do que o efeito de remissão possível a um dizer outro, localizável e repetível.

Um conflito entre os sujeitos da Wikipédia em torno da fonte das informações dispostas nos artigos, nesse caso, se estabelece. Num primeiro momento, é preciso desnaturalizar a própria de fonte da informação, aproximando a SD5 da SD6, que marcam o discurso da Wikipédia, sob o modo de instrução aos wikipedistas:

SD5 - A Wikipédia serve para compilar o conhecimento humano. Não é um meio para tornar opiniões pessoais parte do conhecimento humano. 
SD6 - A Wikipédia contém uma vasta quantidade de informações sobre os mais variados assuntos, para não dizer todos.

Donde extraímos que (1) a Wikipédia compila o conhecimento; e (2) a Wikipédia contém informações sobre todos os assuntos. Logo, há um pré-construído de que informações são conhecimento. Ao tomar informação como conhecimento, um conjunto de redes discursivas se emaranham em torno da significação de informação. Mensurável e decomponível, a noção de informação se revela como um conjunto de elementos distintos, agrupáveis em volume e em natureza e que dizem respeito a soma da experiência humana. O conhecimento, por conseguinte, se mede, quantifica, armazena e registra. A Wikipédia, enquanto compiladora do conhecimento (SD5) tem o papel de acumular informações. Esse pré-construído é reforçado ainda em outra instrução (SD7, abaixo), indo ao encontro do que analisamos sobre a imparcialidade. Um efeito de sentido para ineditismo da informação emerge no fio do discurso quando a toma como lugar para colocar informações. Como na SD abaixo:

SD7 - A Wikipédia não é lugar para publicar suas próprias idéias, nem para colocar informações ainda não publicadas por outros meios.

Como analisamos anteriormente, há um implícito na discursivização da Wikipédia de que as informações devem ter sido publicadas em outros meios, garantido-lhes, portanto, o efeito de anterioridade do dizer, confiabilidade, cientificidade e verificabilidade. Esse efeito é que emerge no dizer dos sujeitos que buscam, como wikipedistas, garantir que as informações (sob efeito parafrástico de sentido de conhecimento) tenham fontes confiáveis, isto é, possam ser verificadas e reconhecidas sob o efeito de origem localizável do dizer. Esse efeito suscita no discurso uma aparente tranquilidade, um "porto seguro" em que o sujeito se agarra como senhor do que diz e do que lê, uma vez que, o sentido se estabiliza pela verificação, em seu efeito de evidência, de garantia, de indubitabilidade.

É nesta conjuntura que emergem formulações como a constitutiva da SD que segue.

SD8 - Isso mesmo Guilherme! Apesar de ser filho desta cidade marvilhosa, eu não ousaria dizer essas coisas. Dados confiáveis é o que importa. Quando penso em UFRJ, penso mais ainda em USP, em UFMG, em UFLA, em UFSCAR. Não dá para afirmar uma coisa assim... é isso aí. crespus2006 (discussão) 04h09min de 4 de Janeiro de 2008 (UTC)

Assim, o sujeito do discurso se nega a ousadia de dizer certas coisas sobre a cidade. Ao negar certos dizeres, emerge, pelo trabalho da história na língua, uma interdição, um limite, uma regra que não deve ser transgredida e que diz respeito aos dados. E aqui informações sofre um deslocamento de sentido para dados. Essa deriva ratifica a tomada de informação como unidade acumulável. Os dados, pois, devem ser confiáveis. Portanto, na naturalização do sentido de confiáveis, temos dois movimentos distintos do sujeito do discurso: (1) sua submissão a um princípio exterior e maior, que regula seu dizer e (2) a certeza de que a confiabilidade nao está no seu dizer, pois do contrário sua palavra bastaria. Esses dois movimentos correspondem, no plano do discurso, à determinação do sujeito e do sentido, pela identificação com a forma-sujeito da FD que regula, mais uma vez, o efeito de caráter enciclopédico de que se revestem os artigos na Wikipédia. Esse efeito de confiabilidade revela a contradição constitutiva da enciclopédia: ainda que armazenando todo o conhecimento, ela, por si só, não garante a 
veracidade desse conhecimento, exigindo a referência, isto é, a remissão, a elementos de saber presentes em outros espaços possíveis, em outras materializações.

Na página de discussão sobre "ISO (Internacional Standard Organization)", um outro editor marca seus gestos na Wikipédia. Detenhamo-nos na menção aos dados.

SD9 - Tomei a liberdade de incluir no artigo alguns dados disponíveis no site da ISO internacional creio que esta organização tem a credibilidade necessária para definir sua origem e a definição do seu nome. Caso seja encontrado outro autor ou organização defendendo outra teoria com relação a origem da palavra ISO ou mesmo outra definição para o nome da organização, acho interresante que fosse compartilhado com todos, pois o objetivo do wikipédia é o compartilhamento das informações da forma mais imparcial possível e de fontes fidedignas. Paulo Dias 09:24, 23 Março 2007 (UTC)

Pela presença dos ditos na SD podemos traçar a relação com não-ditos que corresponderiam, então, à negação da confiabilidade.

\begin{tabular}{|l|l|}
\hline \multicolumn{1}{|c|}{ Confiável } & \multicolumn{1}{|c|}{ Não confiável } \\
\hline Dados disponíveis no site da ISO & Outra definição \\
Organizaçao com crebilidade (seu próprio & Outra teoria sobre o nome \\
nome) & Não compartilhamento das \\
Fonte fidedigna & informações \\
\hline
\end{tabular}

Nessa SD o sujeito estabelece a relação de confiabilidade entre os dados disponibilizados no artigo. Há um esforço dos sujeitos na Wikipédia para "enquadrarem-se" no princípio de verificabilidade, pois, ainda que a linguagem seja incompleta e os sentidos lhes escapem, o sujeito "ousa" e toma uma posição da qual seu dizer é veiculado como verdadeiro e fiel às fontes dado o gesto de referenciação.

Podemos visualizar, pelo viés dos princípios de verificabilidade e imparcialidade, que os sujeitos na Wikipédia buscam atingir uma idealização discursivamente construída e sobre a qual lançam seus esforços na escrita de cada verbete. Longe de preconizarem pelas suas práticas a liberdade tão proferida no próprio slogan da enciclopédia, seus dizeres são altamente regulados por mecanismos discursivos nos quais determinados padrões são avidamente almejados e seguidos (ao menos no plano da tentativa). Mais do que isso, esses mecanismos funcionam como critérios para um comportamento policialesco entre os editores, que vigiam-se uns aos outros para verificar se estão mais ou menos próximos dessas idealizações.

\section{CONSIDERAÇÕES FINAIS}

No jogo pela determinação do sentido, a configuração de imagens (que determina e é determinada pelo lugar discursivo) no plano discursivo através das posições discursivas ocupadas pelos sujeitos do discurso, em sua relação com as situações reais de existência, mostrou-se muito pertinente, e permitiu visualizar o trabalho de formações imaginárias distintas. De um lado, a imagem do enciclopedista: aquele que escreve enciclopédias, e de outro, a imagem do internauta: aquele navega pela rede mundial de computadores. A partir dessas duas imagens bastante diferentes entre si, podemos constatar que as formulações vão ser construídas no espaço do verbete, por sujeitos do discurso que, buscam atender a essas duas imagens simultaneamente, passando a uma idealização que culmina na figura de uma terceira 
imagem: a imagem do wikipedista. Portanto, é o wikipedista a correspondência no plano da designação, de uma construção imaginária da figura do internauta como aquele que se vale de todos os recursos da web e que tem liberdade para expressar-se e trocar com outros internautas e que é um enciclopedista dentro do universo virtual.

Através da análise ainda podemos concluir que, em relação aos sujeitos envolvidos na Wikipédia, temos duas naturezas distintas: a da idealização, na qual há uma imagem construída e sobre a qual uma série de princípios são produzidos para regular os dizeres e os saberes acerca do conhecimento humano (o wikipedista); e a da realização, na qual os sujeitos dos discursos (dotados de inconsciente e pela ideologia interpelados) vão produzindo seus dizeres e mobilizando saberes acerca do conhecimento humano na tentativa (nunca concretizada) de total enquadramento na imagem construída (os editores).

\section{BIBLIOGRAFIA}

GRIGOLETTO, Evandra. Do lugar discursivo à posição-sujeito: os movimentos do sujeito-jornalista no discurso de divulgação científica. In: MITTMANN, Solange; GRIGOLETTO, Evandra; CAZARIN, Ercília Ana. Práticas Discursivas e identitárias: sujeito e língua. Porto Alegre: Nova Prova, 2008. Págs.47-65.

HENRY, Paul. Os fundamentos teóricos da Análise Automática do Discurso de Michel Pêcheux (1969). In: GADET,F.;HAK,T. Por uma análise automática do discurso: uma introdução à obra de Michel Pêcheux. Campinas, SP: Ed.da UNICAMP, 1997. P. 1338.

LEANDRO FERREIRA, Maria Cristina. A trama enfática do sujeito. In: Análise do Discurso no Brasil:mapeando conceitos, confrontando limites. São Carlos: Claraluz, 2007. p. 101-108.

MARIANI, Bethania. Sujeito e discursos contemporâneos. In: INDURSKY, F.; LEANDRO FERREIRA, M.C.; MITTMANN, S.O discurso na contemporaneidade: materialidades e fronteiras. São Carlos: Clara Luz, 2009 (no prelo).

MORALES, Blanca de Souza Vieira. Sujeito: imaginário, simbólico e real. In: MITTMANN, Solange; GRIGOLETTO, Evandra; CAZARIN, Ercília Ana. Práticas Discursivas e identitárias: sujeito e língua. Porto Alegre: Nova Prova, 2008. P.34-46.

ORLANDI, Eni P. A questão do assujeitamento: um caso de determinação histórica. [online]Disponível em:

http://www.comciencia.br/comciencia/handler.php?section=8\&edicao=26\&id=296. Arquivo acessado em 23/04/2009.

PÊCHEUX, Michel. Análise Automática do Discurso (AAD-69). In: GADET, Françoise; HAK, Tony (orgs.). Por uma análise à obra de Michel Pêcheux. Campinas: Unicamp, 1997a. P. 61-161.

PÊCHEUX, Michel. Semântica e Discurso: uma crítica à afirmação do óbvio. Campinas: Unicamp, 1988.

PÊCHEUX, Michel; FUCHS, Catherine. A propósito da análise automática do discurso: atualizações e perspectivas (1975). In: GADET, Françoise; HAK, Tony (orgs.). Por uma análise à obra de Michel Pêcheux. Campinas: Unicamp, 1997. P.163-252. 